\title{
Para uma sintaxe diacrônica das sentenças copulares do português
}

\author{
Marcelo Amorim Sibaldo \\ Doutor em Linguística pela Universidade \\ Federal de Alagoas, Professor Adjunto II da \\ Universidade Federal Rural de Pernambuco, \\ Unidade Acadêmica de Serra Talhada, e Líder \\ do Grupo de Estudos em Teoria da Gramática \\ (GETEGRA). Esta pesquisa está sendo financiada \\ pela Fundação de Amparo à Ciência e Tecnologia \\ do Estado de Pernambuco (FACEPE), processo \\ APQ-1117-8.01/10.
}

Resumo: Com o intuito de observar a mudança sintática das línguas naturais, este artigo objetiva apresentar três fenômenos sintáticos, que são

Abstract: This article aims at presenting three syntactic phenomena, which are brought by copular sentences of Portuguese, with the apresentados nas sentenças copulares do português. A discussão é gerada acerca: (i) da concordância entre 0 sujeito e o predicado daqueles tipos de sentenças; (ii) do verbo cópula ser enquanto verbo existencial, diacronicamente; e (iii) de purpose of observing syntactic changes in natural languages. This discussion is developed around: (i) the agreement between the subject and the predicate of the aforementioned type of sentences; sintagmas preposicionais com conteúdo semântico (ii) the copula verb ser as a verb of existence, diachronically; and (iii) prepositional phrases diferenciados, quando estes constituem predicado de with differentiated semantic content, when they estruturas copulares. constitute a predicate of copular sentences.

Palavras-Chave: Sintaxe; Português arcaico; Predicação; Sentenças copulares; Mudança; Keywords: Syntax; Old Portuguese; Predication; Variação Copular Sentences; Changes; Variation 



\section{Introdução}

Neste artigo, apresentaremos algumas questões ainda não muito discutidas acerca da sintaxe do português brasileiro, mais especificamente, traremos à tona questões relacionadas às sentenças copulares do português, sentenças essas que há muito têm sido relegadas estudos, principalmente quando se trata de sua função enquanto cópula, pois, apesar de alguns estudos terem se debruçado sobre os verbos ser e estar enquanto verbos auxiliares (cf. ALMEIDA, 2006; GUILHERME, 2009; RIBEIRO, 1996; entre muitos outros), poucos estudos pesquisaram a atuação desse tipo de verbo, no português brasileiro, enquanto fazendo a ligação entre um sujeito e um predicado, ou seja, atuando apenas como uma cópula, como nos exemplos abaixo:

(1) a. O trabalho está pronto.

b. Eu estou ferido.

c. O João é médico.

d. Eu sou seu amigo.

Diante do que foi assinalado acima, o objetivo principal deste artigo é trazer alguns temas trabalhados no projeto de pesquisa, por nós coordenado, intitulado $A$ Sintaxe das Sentenças Copulares: Diacronia e Sincronia no Português Pernambucano, que almeja descrever e explicar fenômenos concernentesà sintaxedoportuguês, mapeando as mudanças linguísticas que ocorreram no período do século XVII até o século XXI, a fim de contribuir com os estudos diacrônicos do português, mais especificamente, com o estudo das sentenças copulares, isto é, sentenças que, de acordo com a gramática normativa, tem um predicado nominal, ou seja, uma sentença que possui um sujeito, uma cópula verbal (discorreremos apenas sobre as cópulas ser e estar) e um predicado, seja ele de natureza adjetival, nominal, adverbial ou, ainda, preposicional. Como nos diz Paixão de Sousa (2004, p. 9), "[o] interesse da teoria da gramática pela história das línguas remete a 
possibilidade do estudo da mudança gramatical entendida como fenômeno de aquisição de linguagem, no qual uma determinada geração de falantes chega a adquirir uma gramática distinta da geração anterior”. Assim, no quadro gerativo, o estudo da mudança linguística envolve, de certa forma, "a reconstrução e as técnicas comparativas - pois o que dá partida para as análises é a constatação de diferenças entre os fatos da língua atual e os fatos passados das línguas." (idem, ibidem).

$\mathrm{O}$ que, na verdade, objetivamos aqui é contribuir para uma agenda de pesquisa acerca das construções copulares, a fim de que se busque o aprofundamento a respeite de três fenômenos linguísticos, entre outros, concernentes a essas sentenças, tão pouco estudas e talvez por serem pouco estudadas - pouco entendidas na literatura linguística, principalmente se formos levar em consideração estudos diacrônicos feitos no estado de Pernambuco. O primeiro desses fenômenos diz respeito ao status de verbo existencial da cópula seer do português arcaico até a cópula ser do português brasileiro atual. Examinaremos em que século do português (i) houve uma queda no uso da cópula enquanto verbo existencial e (ii) emergiu-se o uso do ter também como verbo existencial. Para atingir esses objetivos, usaremos a metodologia da Teoria da Variação e Mudança Linguísticas, a fim de quantificar os dados e identificar exatamente em que período da história do português começou-se essa possível mudança de verbos existenciais, uma vez que o verbo ser parece estar em declive quando do seu uso enquanto verbo existencial no português brasileiro (cf. AVELAR, 2004, AVELAR; CALLOU, 2000; VIOTTI, 1999; entre muitos outros). Já para a análise desses dados e explicar o porquê de o verbo ter passar a existencial, em detrimento do ser, usaremos o quadro teórico da Gramática Gerativa no seu modelo de Princípios \& Parâmetros (cf. CHOMSKY, 1981 e 1986). O segundo fenômeno a ser examinado diacronicamente diz respeito aos casos de concordância entre os elementos das sentenças copulares, especificamente, a concordância 
entre o sujeito, a cópula e o predicado, quando o sujeito é um sintagma nominal com morfologia visível de número ou um sintagma nominal composto e o predicado é um sintagma nominal sem nenhuma morfologia de número, pois é fato que, no português brasileiro, língua semi-prodrop (cf. COELHO, 2000 e TAVARES SILVA, 2004), nesses casos, a cópula pode concordar tanto com o sujeito quanto com predicado e, sendo assim, o objetivo da análise deste fenômeno é o de comparar com o português arcaico a fim de se verificar se esta língua, no que diz respeito à concordância em sentenças copulares, assemelha-se ao italiano (língua pro-drop) ou ao inglês (língua não prodrop). Finalmente, o terceiro fenômeno sobre o qual nos debruçaremos procura diagnosticar questões sintáticosemânticas acerca dos sintagmas preposicionais, que são selecionados como predicados de construções copulares, pois, como se sabe, no português brasileiro, a seleção de cópula + PP pode culminar em papéis temáticos (ideias semânticas) distintos, a depender da semântica expressa no PP pós-cópula (locativo, companhia, posse, matéria etc.). Entretanto, pouco se sabe se os mesmos contextos sintático-semânticos do português brasileiro poderiam ser replicados no português arcaico. A nossa intuição é a de que outras construções copulares tenham sofrido mudança (tanto sintática quanto semântica) do português arcaico até chegar ao português brasileiro. Dados os três fenômenos a serem trabalhados neste projeto, é interessante pontuar que, a fim de que a descrição e análise linguísticas se deem de forma complementar, duas perspectivas teóricas se fazem necessárias, para a análise dos fenômenos a serem estudados: de um lado, a metodologia do quadro teórico da sociolinguística variacionista, como delineada em Weinreich, Labov \& Herzog (1968) e Labov (1972 e 1994) e, de outro, o aparato teórico dos postulados da Teoria Gerativa na sua versão de Princípios \& Parâmetros (CHOMSKY, 1981 e 1986).

É importante salientar que, no que se refere aos estudos formais da língua portuguesa, o projeto A Sintaxe das Sentenças Copulares: Diacronia e Sincronia 
no Português Pernambucano, acima referido, visa ao desenvolvimento de uma investigação pioneira, pois, tanto quanto saibamos, as construções copulares no português são muito pouco estudadas, seja em estudos sincrônicos ou seja em estudos diacrônicos, seja em Portugal seja no Brasil, e, se formos levar em consideração a região nordeste, mais especificamente, o estado de Pernambuco, o estudo diacrônico sobre as sentenças copulares é quase inexistente (ou inexistente); o que não acontece nos estudos das sentenças copulares do inglês (cf. DECLERCK, 1988; HIGGINS, 1976; PARTEE, 1999; entre muitos outros) ou do hebraico (cf. DORON, 1983; GREENBERG, 1994; RAPOPORT, 1987; entre muitos outros), por exemplo. Uma possível explicação para essa escassez de estudos que se debrucem sobre as construções copulares do português (ou, então, o resultado dessa falta de reflexão em torno dessas sentenças) vem da afirmação presente na recém-lançada "Nova Gramática do Português Brasileiro", de Castilho (2010, p. 397): "[a]s diferenças sintáticas constatadas entre ser e estar constituem um dos mais desafiadores problemas da língua portuguesa, maiormente quando a comparamos às línguas românicas". Cumpre salientar que o referido projeto conta com a participação de três bolsistas de Iniciação Científica, a saber, Iane Siqueira Correia, José Luiz de Brito Coelho e Thamires dos Santos Izídio, a fim de que sejam pesquisados os temas aqui retratados.

Sendo assim, esta pesquisa vem precisamente para tentar sanar essa lacuna nos estudos linguísticos do português, principalmente no que se refere ao português brasileiro pernambucano, uma vez que seu intuito é o de estudar três aspectos sintáticos relacionados às construções copulares do português, insuficientemente compreendidos até então, por meio de uma investigação diacrônica, que nos parece ser primordial para os casos aqui estudados, pois, a nosso entender, o estudo diacrônico possibilita análises aprofundadas sobre os diferentes estágios da língua a fim de se lançar alguma luz sobre "um dos mais desafiadores problemas da língua portuguesa" do qual fala Castilho. 
Os dados selecionados para a análise que comporão o corpus da pesquisa, que ainda está em fase preliminar, serão delimitados da seguinte forma: sentenças copulares com contextos declarativos finitos e, desses tipos de sentenças, serão analisados três contextos: a função de verbo cópula enquanto um verbo existencial; a concordância entre sujeito, cópula e predicado nas sentenças copulares; e o papel sintático-semântico exercido pelo predicado, quando este é um sintagma preposicional. Selecionados os dados, proceder-se-á, de início, à análise em termos não só quantitativos, mas também qualitativos com base nas variáveis linguísticas selecionadas. Feita essa análise, dar-se-á início à análise teórica, lançando-se mão do aparato teórico da Teoria Gerativa em sua versão de Princípios \& Parâmetros (CHOMSKY, 1981 e 1986), no que concerne às teorias de Caso, temática e os mecanismos de concordância. Entretanto, como dissemos, neste artigo, faremos apenas uma breve explanação dos dados, uma vez que a pesquisa se encontra no início.

$\mathrm{Na}$ próxima seção, discutiremos a noção de cópula e de sentenças cópulas; na seção 3, apresentaremos as cópulas do português brasileiro; na seção 4, apresentaremos o fenômeno do verbo copular "ser" enquanto existencial; na seção 5, discutiremos acerca de questões relacionadas à concordância nas sentenças copulares; na seção 6 , trataremos da seleção de sintagmas preposicionais enquanto predicado de sentenças copulares; na seção 7 , finalizaremos o artigo com um apanhado geral do que foi discutido.

\section{Sobre Cópula e Sentenças Copulares}

Desde a tradição filosófica ocidental, perpassando pelo período da Linguística pré-saussureana até chegar à Linguística moderna, muitas foram as definições de sentença. O sofista, de Platão, foi o primeiro livro (de acordo com SEUREN, 1998) a definir "sentença" como uma junção de um sujeito e um predicado, uma 
idéia que foi tomada posteriormente por Aristóteles, mais especificamente em Perì Hermēneías (De Interpretatione, no latim, como esta obra é comumente conhecida), onde tais noções são essenciais tanto num plano gramatical quanto num plano lógico. Para o propósito desta seção, deter-nos-emos à noção de "predicado" para Aristóteles, tentando precisar a noção de cópula para este filósofo.

$\mathrm{Na}$ tradução de Ackrill (1963) para o inglês do texto de Aristóteles, o que é dito sobre sentença declarativa é que: "[e]very statement-making sentence must contain a verb or an inflection of a verb" (De Interpretatione, 5, 17a, 12) porque "a verb is a sign of what holds, that is, holds of a subject" (De Interpretatione, 3, 16b, 7). A tradução de Ackrill é potencialmente enganadora e o que está em jogo na segunda parte da citação é, na verdade, o "predicado" e não o "verbo", como observado por Moro (1997, p. 250). A palavra rhêma do grego é uma palavra que se torna ambígua quando traduzida para o português ou inglês, visto que ela pode figurar tanto como verbo (verb, no inglês) quanto como predicado (predicate). Sendo assim, alguns trechos de algumas traduções de De Interpretatione são comprometidos nesse sentido. Retomando as citações acima, depreendemos que, para Aristóteles, os primitivos conceituais constituintes de uma sentença declarativa são um sujeito, um predicado e uma especificação de tempo.

Para Aristóteles, a cópula é desvinculada do predicado, sendo considerada o elemento que fornece à sentença declarativa a sua especificação de tempo. Assim, uma sentença declarativa baseada na assunção aristotélica, consiste em uma "ligação predicacional" mais especificações de tempo. A cópula estaria em distribuição complementar com a flexão verbal.

Outra visão acerca da cópula é a perspectiva de que este elemento faz parte do predicado em si, partilhada pelo matemático Bertrand Russel. Em seu 
livro Introduction to the Philosophy of Mathematics (RUSSEL, 1919), este autor argumenta que a cópula pode tanto expressar uma relação entre o sujeito e o predicado, como em Socrates is human, quanto expressar uma identidade, como em Socrates is a man. De acordo com as palavras desse matemático: "[i]t is a disgrace to the human race that it has chosen the same word is for those two such entirely different ideas as predication and identity - a disgrace which a symbolic logical language of course remedies." (cf. RUSSEL, 1919, p. 172). Assim, para este autor, a cópula é ambígua, podendo fazer o papel tanto de uma predicação, como em Socrates is human, quanto de uma identidade, como em Socrates is a man, onde a cópula seria um predicado e faria papel de um sinal de igualdade "=" nesse tipo de sentença. O trabalho de Russel teve um grande impacto nos estudos linguísticos do século XIX, como pode ser visto na tipologia das sentenças copulares criada por Higgins (1976), na seção 1.3.

O viés de Russel é também partilhado pela gramática de Montague (cf. MONTAGUE, 1973; DOWTY, WALL \& PETERS, 1981; PARTEE, 1999), que faz a distinção entre dois tipos de cópula be, do inglês, a saber: a cópula be de predicação e a cópula be de identidade, tal separação é feita a depender dos tipos semânticos dos seus argumentos. Assim, o be de predicação, como em Socrates is human (para usar os exemplos de Russel), toma dois argumentos de tipos e e $<\mathrm{e}$, $\mathrm{t}>\mathrm{e}$ sua semântica é $\lambda P . \lambda x[\mathrm{P}(\mathrm{x})]$. Em outras palavras, isso implica o predicado ao sujeito. Por outro lado, o be de identidade, como em Socrates is a man, toma dois argumentos do tipo e e sua semântica é $\lambda \mathrm{x} . \lambda \mathrm{y}[\mathrm{x}=\mathrm{y}]$. Em outras palavras, isso expressa a identidade de seus dois argumentos.

Advinda do latim, a palavra copulare pode ser traduzida como "ligação", o que explica o porquê de nossas gramáticas tradicionais considerarem os verbos ser, estar, ficar etc. como verbos de ligação. Assim, o "verbo de ligação" faz a conexão entre dois sintagmas distintos.
${ }^{2}$ Na semântica formal, dizemos que um constituinte sintático do tipo "e" pertence ao domínio das entidades, enquanto que um constituinte sintático do tipo " $t$ " pertence ao conjunto dos valores de verdade. Para um curso introdutório de semântica formal e a notação lambda aqui utilizada, ver Heim \& Kratzer (1998), Ferreira (em preparação) e Chierchia \& McConnellGinet (1990). 
Para os propósitos deste artigo, diremos simplesmente que a cópula é o termo que liga um sujeito a um predicado.

A favor da formulação de uma tipologia para as sentenças copulares, Higgins (1976), num trabalho clássico, elabora uma terminologia diferenciada para cada tipo de sentença copular (e não estruturas diferenciadas!). De acordo com este autor, há uma distinção entre as estruturas de cópula em quatro tipos: além das estruturas predicacionais e de identidade (ou equativa), ele acrescenta mais duas categorias a esta tipologia, a saber: a especificacional e a identificacional, como elencado em (2) abaixo:

(2) a. O João é um assaltante de bancos. Predicacional b.O assaltante de bancos é o João. Especificacional

c. A estrela da tarde é a estrela da manhã. Identidade d.Aquele lugar é a Ponta Verde. Identificacional

As sentenças predicacionais atribuem alguma propriedade ao sujeito (cf. (3a)). As sentenças especificacionais "merely says what one is talking about: the Subject in some way delimits a domain and the Specificational Predicate identifies a particular member of that domain" (Higgins, 1976, p. 132) (cf. (3b)). As sentenças de identidade "express an identity 'is' or ' $=$ ' must stand between two noun-phrases which, if they are distinct, are serving independently of one another to make genuine references" (cf. Wiggins, 1967, p.42 apud Higgins, op. cit., p. 165) (cf. (3c)). Já as sentenças identificacionais são "typically used for teaching the names of people or of things" (Higgins, op.cit., p. 147) (cf. (3d)).

\section{Sobre as Cópulas do Português Brasileiro}

Translinguisticamente, a cópula pode assumir diversas formas. Em muitas línguas já estudadas, pode-se 
afirmar que há dois ou mais tipos de elementos cópula. Stassen (1997), por exemplo, divide as cópulas em três tipos, com base na sua origem histórica. Elas podem ser: (i) verbais, (ii) pronominais e (iii) cópulas-partículas.

Como sabido, no português brasileiro (doravante $\mathrm{PB}$ ), assim como no espanhol, por exemplo, a cópula é realizada através de verbos, pelo menos, dois tipos de verbos-cópula, a saber, o "ser" (do latim sedēre, que significa "estar sentado) e o "estar" (do latim stare, que significa "estar de pé"). ${ }^{1}$ A diferença básica comumente atribuída às duas cópulas verbais seria a de que o predicado com a cópula ser estaria tipicamente "associado a propriedades intrínsecas, interpretadas como imanentes ou, pelo menos, a atributos com efeito mais permansivo" (cf. AVELAR, 2004, p. 181), já o predicado associado a estar seria caracterizado "como suporte de uma atribuição adquirida e/ ou como uma expressão que remete a condições mais passageiras" (cf. AVELAR, idem, ibidem). Se fôssemos usar os termos propostos por Carlson (1977) ${ }^{2}$, poderíamos associar, grosso modo, a cópula ser do PB a construções do tipo individual level e, por outro lado, também poderíamos associar a copula estar a construções do tipo stage level. Desse modo, o significado de um determinado predicado muda de acordo com a cópula selecionada. $\mathrm{O}$ que foi dito, pode ser exemplificado com os dados do $\mathrm{PB}$, arrolados abaixo:

(3) a. O João está gordo. Construções de tipo Stage Level b.A Maria está muito feia.

c. As crianças estão felizes.

(4) a. O João é gordo. Construções de tipo Individual Level b.A Maria é muito feia.

c. As crianças são felizes.

De outro modo, o que ocorre normalmente nas línguas com um sistema multi-cópula (i. e., línguas em que há mais do que uma única cópula) é uma realização fixada

\footnotetext{
${ }^{1}$ No PB, há, ainda, vários outros

"verbos de ligação", nomeadamente, as chamadas semi-cópulas (cf. MORO, 1997).

Não trataremos destes verbos neste artigo, pois eles, diferentemente dos verbos ser e estar, contêm algum tipo de material semântico.
${ }^{2}$ As ideias de predicados stage e inividual level foram, depois, desenvolvidas em Kratzer (1995) e Diesing (1992). (1992).
} 
${ }^{3}$ Há, porém, casos dependentes de contexto em que um determinado predicado que é tipicamente aceito com um determinado verbo cópula, digamos ser, por exemplo, e que passa a ser aceito com outro verbo cópula, digamos estar, por exemplo. Como em "A Denise está fiel *agora/ ultimamente)", onde um advérbio de tempo é obrigatório. (i. e., lexicalizada) entre um determinado lexema e uma cópula específica. Desse modo, um determinado lexema só pode ser combinado com uma única cópula. Porém, apesar de uma gama de predicados ser compatível tanto com a cópula ser quanto com a estar, também ocorre algo semelhante a estas línguas, nesse sentido, no PB. Sendo assim, alguns predicados só podem ser combinados com o verbo ser ao passo que outros só podem ser combinados com estar: ${ }^{3}$

(5) a. O Rafael está descalço.

b. A Maria está grávida.

a'. * O Rafael é descalço.

b'. *A Maria é grávida.

(6) a. A Denise é fiel.

b. O João é cozinheiro.

a'. *A Denise está fiel.

b'. *O João está cozinheiro.

$\mathrm{Na}$ verdade, como nos alerta Casteleiro (1981, p. 208) apud Mealha (2001, p. 156), a diferença entre ser e estar e a seleção de seu predicado em frases copulativas predicacionais podem estar restritas a alguns fatores importantes, entre alguns, este autor enumera os seguintes:

(i) propriedades sintático-semânticas dos adjetivos;

(ii) contexto lingüístico (isto é, estrutural) e situacional;

(iii)natureza sintático-semântica do sintagma nominal sujeito;

(iv) fenômenos de natureza aspectual e modal;

(v) atitude ou ponto de vista (modal) do sujeito falante (ou autor da enunciação) relativamente ao conteúdo do ato de elocução. 
No que concerne à seleção da natureza categorial do predicado, recentemente, um estudo empírico de cópulas embasado num modelo funcionaltipológico feito por Pustet (2003), baseado em dados de mais de 150 línguas, procurou estabelecer um padrão distribucional existente nas línguas humanas em relação a estes elementos. Como ponto de partida, o estudo empírico de Pustet buscou pesquisar quais os tipos de predicados que podem ser combinados com cópulas. O padrão distribucional existente pode ser englobado, de acordo com os achados desta pesquisa, na seguinte hierarquia implicacional:

(7) NOMINAIS $>$ ADJETIVAIS $>$ VERBAIS ${ }^{4}$

O que a "hierarquia implicacional" revela é que o fenômeno da "copularização" é unidirecional da seguinte forma: "if any class of lexeme copularizes in a given language, the class of nominals does; if any lexical class other than nominals copularizes, the adjectival class does; only if both nominals and adjectivals copularize, verbals may also copularize." (cf. PUSTET, 2003, p. 73). Dito de outra forma: se uma língua permite uma cópula com algum elemento da escala em (7), ela irá também permitir que a mesma cópula se combine com o(s) elemento(s) à esquerda. Por exemplo, se uma língua permite que uma determinada cópula ocorra com elementos adjetivais, ela também irá permitir que a mesma cópula ocorra com nominais, assim como uma língua que permite que uma determinada cópula se combine com um elemento verbal possa se combinar com elementos tanto adjetivais quanto nominais.

A hierarquia implicacional proposta por Pustet (2003) parece, de fato, atuar no PB, haja vista tanto a cópula "ser" quanto a cópula "estar" selecionarem elementos verbais, adjetivais ou nominais, como nos mostram os exemplos abaixo:

${ }^{4}$ Tal hierarquia ignora PPs predicados, talvez pelo status categorial das preposições variar entre lexical e funcional. Sobre o status das preposições no quadro teórico da gramática gerativa, ver Farias (2005). 
(8) a. A sopa está uma delícia.

b. A sopa está velha.

c. A sopa está caindo.

(9) a. A Maria é uma professora.

Ser

b. A Maria é linda.

c. A Maria foi beijada.

Interlinguisticamente, pode-se afirmar que as sentenças copulares são especiais no sentido de que elas podem aparecer de diversas formas, pois, quando a cópula é adicionada a algum outro elemento, surge um razoável número de "cores" e "sabores" de sentenças copulares. Vejamos o caso do inglês, por exemplo, tais construções com a cópula be podem vir como existenciais, locativas, predicativas, equativas (de identidade) etc. E, mais ainda, a cópula pode vir como verbo auxiliar para formar tempos complexos, como em diversas outras línguas:

(10) a. There are gnomes and fairies in these woods.

Existencial

"Tem gnomos e fadas nestas matas."

b. The gnome is in the jar.

Locativa

"O gnomo está no jarro."

c. The fairies are small.

Predicativa

"As fadas são pequenas."

d. Puck is Robin Goodfellow.

Equativa

"O Puck é o Robin Goodfellow."

e. The gnome is building a new house. Auxiliar

"O gnomo está construindo uma casa nova."

(PERELTSVAIG, 2001, p. 5, ex. (7))

Há, ainda, línguas que, diferentes do inglês, por exemplo, usam a mesma cópula de construções como aquelas em (10) para as construções possessivas. Exemplos desse tipo de língua são o hebraico e o russo, que usam a mesma cópula em todas as construções ilustradas acima com o inglês e, ainda, em construções copulares possessivas, como ilustrado abaixo: 
(11) a. Le-Dani haya sefer xadaš. Hebraico para-Dani foi livro novo

"Dani tem um livro novo."

(PERELTSVAIG, 2001, p. 6, ex. (8d))

b. U Tani byli den'gi. Russo (Posse alienável)

em Tani foram dinheiro.PL.NOM

"Tani tem dinheiro."

c. U Tani byli golubye glaza. Russo(Posseinalienável) em Tani foram [olhos azuis].NOM

"Tani tem olhos azuis."

(PERELTSVAIG, 2001, p. 12, ex. (20))

Em resumo, vale dizer, portanto, que as cópulas são construções que diferem de outros verbos, não apenas em português, mas também, como foi visto a partir deste pequeno apanhado sobre as construções copulares, em diversas línguas, uma vez que elas podem se apresentar de diversas formas, a depender de outros elementos adicionados à sentença e/ ou do contexto.

A partir da próxima seção, iremos apresentar alguns fenômenos pouco explorados relacionados àqueles tipos de sentenças. A ideia é contribuir para uma agenda de pesquisas sobre as sentenças copulares e discutir, ainda que sucintamente, alguns pontos sobre esses fenômenos.

\section{A cópula enquanto verbo existencial}

O primeiro dos fenômenos a ser discutido diz respeito a usos que eram bastante comuns em construções copulares no português arcaico e que, no $\mathrm{PB}$, está caindo em desuso, nomeadamente, o uso da cópula enquanto verbo existencial. Como podemos observar adiante, no português arcaico, era bastante comum o uso da cópula seer em contextos existenciais:

(12) a. Na cidade d'Aconha foi hũũ bispo de gram santidade. (foi $=$ existiu)

b. E diz que naquela provincia de Valeria foi hũũ bispo que avia nome Sabino. (foi = existiu)

(MATTOS E SILVA, 2006, p. 148)

c. Deus é. (é $=$ existe) 
No $\mathrm{PB}$, entretanto, dificilmente algum falante usaria o verbo ser com o sentido existencial, pelo menos, se formos considerar os contextos em (12). No lugar, parece-nos que os verbos existir e ter exercem a função que antigamente cabia aos verbos seer e aver (como apontado por AVELAR, 2004 AVELAR; CALLOU, 2000; VIOTTI, 1999; VITÓRIO, 2008; entre outros, o verbo haver do PB também está em desuso como existencial):

(13) a. Tem muita menina bonita em Recife.

b. Tem um livro em cima da mesa.

c. Tem gente que não gosta do Caetano.

(14) a. Antigamente, existiam vários bondinhos em São Paulo.

b. Essa lenda existia no século passado.

c. Existe muito político corrupto por aí.

Estudando este fenômeno, é importante detectar, através de um método quantitativo, em que fase do português arcaico começaram a surgir os primeiros sinais de mudança do verbo existencial seer, do português arcaico, para os verbos ter e existir, do PB. Nesse sentido, Gonçalves (2010, p. 292) dá uma importante contribuição, fazendo um levantamento do emprego de como os verbos ser e haver se comportam ao longo do tempo na história do português, mostrando que, em ambos os verbos, há uma queda considerável no século XX, como nos mostra seu gráfico exibido abaixo:

Figura 1. Emprego dos verbos ser e haver no Português Antigo e

Clássico em comparação com o Português Brasileiro Contemporâneo

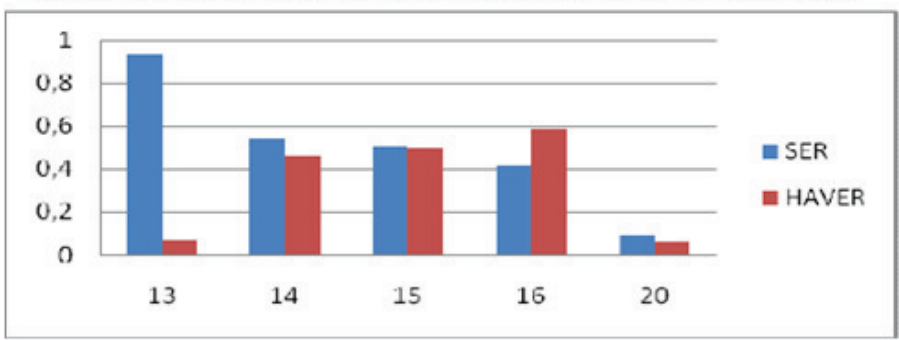

Input: 0.279

Nivel de Significância: 0,010 
Como o gráfico anterior nos mostra, no século XIII há um número considerável (mais de $90 \%$ ) de uso do verbo cópula ser enquanto existencial, o que vai mudando gradativamente, até chegar o século XX, com menos de $10 \%$ de ocorrência. Em trabalhos futuros, tentaremos dar uma explicação sobre o fenômeno dos verbos existenciais no que concerne às estruturas sintáticas disponíveis para essas construções em diferentes fases do português, tendo, como hipótese, a de que, com o passar dos anos, uma determinada categoria funcional, digamos $\mathrm{F}$ (uma categoria (F)uncional qualquer), passou a ser utilizada em determinadas operações morfológicas para a formação desses tipos de verbos, retomando a intuição clássica de Benveniste (1976), de que, grosso modo, um verbo existencial seria um verbo cópula mais a adição de uma preposição abstrata.

\section{A concordância com verbo cópula}

O segundo aspecto a ser colocado na nossa agenda de trabalhos acerca das construções copulares diz respeito a questões de concordância. Assumiremos, com Moro (1997), que a concordância em sentenças copulares é definida através do parâmetro de direcionalidade, ou seja, nas línguas de sujeito não nulo, como o inglês, a concordância é desencadeada pela configuração de especificador-núcleo, que é atestada quando o sujeito de uma determinada sentença está acima do núcleo flexional (I, do inglês Inflection), nomeadamente, na posição de especificador deste núcleo; de outro modo, nas línguas de sujeito nulo, como o italiano, a concordância é realizada através dos traços- $\Phi$ (isto é, os traços gramaticais de pessoa, gênero e número) do sujeito dessas sentenças e, assim, pode ser atestada tanto por especificador-núcleo quanto por regência, a depender da posição estrutural do sujeito da sentença copular ${ }^{5}$, como podemos observar nos exemplos abaixo:

(15) a. John and Mary are the cause of the riot. Inglês "John e Mary são a causa da revolta."

b. *John and Mary is the cause of the riot.
${ }^{5}$ De acordo com Moro (1997), o sintagma [John and Mary]/ [Gianni e Maria], em todas as sentenças de (15)/ (16), é o sujeito, fazendo, assim, uma distinção entre "sujeito" e "posição de sujeito" (cf. HARLEY, 1995). 
${ }^{12}$ De acordo com Moro (1997), o sintagma [John and Mary]/ [Gianni e Maria], em todas as sentenças de (15)/ (16), é o sujeito, fazendo, assim, uma distinção entre "sujeito" e "posição de sujeito" (cf. HARLEY, 1995). Ver a nota 3. c. ${ }^{*}$ The cause of the riot are John and Mary.

d. The cause of the riot is John and Mary.

(16) a. Gianni e Maria sono la causa della rivolta. Italiano

"Gianni e Maria são a causa da revolta."

b. La causa della rivolta sono Gianni e Maria.

c. *La causa della rivolta è Gianni e Maria.

Estudos diacrônicos de cunho gerativista e variacionista, entretanto, têm mostrado que o $\mathrm{PB}$, devido - principalmente - a um robusto enfraquecimento no seu paradigma de flexões verbais, vem sofrendo uma mudança paramétrica no que diz respeito a esse parâmetro no sentido de que estaria passando de uma língua pro-drop, como o italiano, por exemplo, para uma língua não pro-drop, como o inglês (ver DUARTE, 1993; TORRES MORAIS, 1993; entre outros). Tal conclusão pode ser corroborada através dos dados em (17), que assinalam que o PB comporta-se de modo diferente do inglês e do italiano, uma vez que a concordância é atestada tanto com o sujeito quanto com o predicado de uma sentença copular:

(17) a. O João e a Maria são a causa da revolta. Português brasileiro

b. O João e a Maria é a causa da revolta.

c. A causa da revolta são o João e a Maria.

d. A causa da revolta é o João e a Maria.

Dado que o PB é uma língua semi-pro-drop (cf. COELHO, 2000 e TAVARES SILVA, 2004), ou seja, não é nem de sujeito nulo nem de sujeito não-nulo por completo, pois apesar da perda considerável da morfologia verbal, esta língua permite sujeitos nulos em alguns contextos (ver TAVARES SILVA, 2004, para os referidos contextos), a nossa hipótese para esta pesquisa é a de que o "parâmetro de direcionalidade" de Moro (1997) é, na verdade, mais uma das propriedades relacionadas ao parâmetro do sujeito nulo arroladas em Chomsky (1981, p. 241), a saber: 
(i) sujeito nulo;

(ii) inversão livre do sujeito;

(iii) extração do sujeito à distância;

(iv) resumptivo nulo do sujeito; e

(v) ausência do efeito *that-trace.

Sendo assim, o parâmetro de direcionalidade de Moro (1997) será testado com os dados do português arcaico ao $\mathrm{PB}$ sincrônico, fazendo, assim, um levantamento diacrônico dos dados do português pernambucano do século XVII ao XXI para confirmar ou refutar esta hipótese, visto que, se o parâmetro de direcionalidade proposto por Moro se mostrar atuante no PB e ele for uma propriedade relacionada ao parâmetro do sujeito nulo, o português arcaico, língua de sujeito nulo, deve mostrar dados robustos onde são os traços- $\Phi$ do sujeito de uma sentença copular que desencadeia a concordância com a flexão verbal, como ocorre com os dados do italiano em (16).

\section{Os sintagmas preposicionais em construções copulares}

Por fim, o terceiro fenômeno a ser indicado à agenda, neste artigo, diz respeito a questões sintáticosemânticas acerca dos sintagmas preposicionais (doravante PP, do inglês Prepositional Phrase), que funcionam como predicados de construções copulares, pois, como se sabe, no $\mathrm{PB}$, a seleção de cópula $+\mathrm{PP}$ pode culminar em papéis temáticos (ideias semânticas) distintos, a depender da semântica expressa no PP póscópula. É relevante salientar, ainda, que, a seleção das cópulas ser/ estar, nesses casos, é fixa (diferentemente, por exemplo, de sentenças como O João é/ está feliz, cuja seleção pode ser tanto da cópula ser quanto da estar), não podendo haver permuta dessas cópulas. Para enumerar apenas alguns exemplos, vejamos o contraste exibido entre (18) e (19) a seguir: 
(18) a. A Denise está / *é [ ${ }_{P P}$ na praia]. Locativo

b. A Denilda está / *é [ ${ }_{\mathrm{PP}}$ com os orientandos].

Companhia

c. O Marcos está / *é [ ${ }_{\mathrm{PP}}$ com dinheiro]. Posse

d. O feijão está / *é por/ [ ${ }_{\mathrm{PP}}$ de cinco reais].

Preço

(19) a. Essa chave é / *está ${ }_{P P}$ de ouro]. Matéria

b. O dinheiro é / *está [ ${ }_{\mathrm{PP}}$ pra o Manoel]. Beneficiário

c. Este tapete é / *está [ ${ }_{\mathrm{PP}}$ da China]. Origem

d. A missa é / *está [ ${ }_{P P}$ de sete horas]. Tempo

Apesar de, como visto acima, a seleção da cópula neste fenômeno ser fixa no $\mathrm{PB}$, sabemos que, no português arcaico, algumas ideias semânticas, como a de companhia, por exemplo, eram determinadas a partir da junção do PP à cópula seer, como pode ser visto em (20):

(20) ... e que en outro dia seeriam com ele.

(MATTOS E SILVA, 2006, p. 151, ex. (6))

No PB atual, no entanto, esta possibilidade está excluída, salvo casos "fossilizados", como, por exemplo, a oração que os católicos rezam:

(21) Ave Maria, cheia de graça, o Senhor é convosco...

Em relação à PPs que dão a ideia de lugar, também observamos inicialmente que há uma mudança de cópula, igualmente percebida com PPs de companhia, como vemos abaixo (cf. MATTOS E SILVA, 2006):

(22) a. A alma he no corpo. (= estão)

b. Almas que son no outro mundo. (= estão)

A nossa hipótese é a de que outras construções copulares tenham sofrido mudança do português arcaico, além das ideias de companhia e lugar, até chegar ao PB. 
Sendo assim, entendemos que a ideia inicial traçada aqui necessita de um estudo mais aprofundado, uma vez que aqui delineamos apenas os problemas, mas entendemos que pouco se pode fazer, dada a falta de dados robustos.

A perspectiva teórica que pretendemos assumir para dar tratamento aos fenômenos de mudança sintática delimitados aqui busca conciliar a gradação empírica observada entre formas em variação e uma interpretação gramatical (estrutural) da mudança (cf. KROCH, 1989). Seguindo esses preceitos, a coleta e a organização do corpus serão feitas a partir de textos escritos (documentos, jornais, peças de teatro, cartas pessoais etc.) por brasileiros nascidos no estado de Pernambuco (PE) e/ ou por autores portugueses que se encontravam em Pernambuco em séculos anteriores, mais especificamente, no período que vai do século XVII ao século XXI, a fim de descrever e analisar os fenômenos linguísticos relacionados a

processos de variação/mudança do português escrito nesse estado.

\section{Considerações Finais}

Procuramos mostrar neste artigo como a origem e o status do termo cópula na atual conjuntura da teoria Linguística, discriminando e caracterizando as cópulas do português e as construções de cópula. Mostramos, ainda, a partir de um banco de dados ainda limitado, alguns fenômenos que carecem de uma maior descrição e explicação das pesquisas linguísticas, pois, tanto quanto saibamos, aos fenômenos aqui descritos, ainda não foi dada a atenção devida. Como falamos anteriormente, o projeto por nós coordenado, $A$ sintaxe das sentenças copulares: diacronia e sincronia no português pernambucano, vem sanar essa lacuna, buscando responder, através de uma comparação sistemática entre os períodos do português e de outras línguas românicas, qual o status dos verbos copulares no português brasileiro. 


\section{Referências}

ADGER, D.; RAMCHAND, G. Predication and Equation. Linguistic Inquiry, vol. 34, n. 3, 2003. pp. 325-359.

ALMEIDA, E. S. de. A formação de perífrases verbais no português: um processo diacrônico. Dissertação (Mestrado em Linguística), UFRJ, 2006.

AVELAR, J de O. Dinâmicas Morfossintáticas com Ter, Ser e Estar em Português Brasileiro. Dissertação (Mestrado em Linguística), Instituto de Estudos da Linguagem, UNICAMP, Campinas, 2004.

AVELAR, J.; CALLOU, D. Sobre ter e haver em construções existenciais: variação e mudança no português do Brasil. Gragoatá, 9, 2000. p. 85-100.

BENVENISTE, É. "Ser” e “Ter” nas suas Funções Lingüísticas. In: BENVENISTE, Émile. Problemas de Lingüística Geral. São Paulo: Companhia Editora Nacional, 1976. pp. 204-227.

BERLINCK, R. de A.; BARBOSA, J. B.; MARINE, T. de C. Reflexões teórico-metodológicas sobre fontes para o estudo histórico da língua. Revista da $A B R A L I N$, v. 7, n. 2, p. 169195, jul./dez. 2008.

CARLSON, G. Reference to Kinds in English. Ph.D thesis. University of Massachusetts at Amherst, 1977.

CASTELEIRO, J. M. Sintaxe transformacional do adjectivo: regência das construções completivas, Lisboa, INIC, 1981.

CAStilHO, A. T. de. Nova Gramática do Português Brasileiro. São Paulo: Contexto, 2010.

CHOMSKY, N. Aspectos da teoria da sintaxe. 2. ed. Coimbra: Armênio Amado, 1978. [1965]. 
CHOMSKY, N. Lectures on Government and Binding.

Dordrecht: Foris, 1981.

CHOMSKY, N. Knowledge of Language: Its Nature, Origin and Use. New York: Praeger, 1986.

COELHO, I. L. A ordem VDP em construções monoargumentais: uma restrição sintático-semântica. Tese (Doutorado em Lingüística), Universidade Federal de Santa Catarina, Florianópolis, 2000.

COELHO, S. M. Estudo diacrônico do processo de expansão gramatical e lexical dos itens ter, haver, ser, estar e ir na língua portuguesa. Tese (Doutorado em Linguística). $323 \mathrm{f}$. Faculdade de Letras, Universidade Federal de Minas Gerais, Belo Horizonte, 2006.

COSTA, J. L'Opposition SER/ESTAR en Portugais. In: ROUVERET, A. (Ed.). "Etre" et "avoir" (Syntaxe, Semantique, Typologie). Saint-Denis, Presses Universitaires de Vincennes, 1998. pp. 139-153.

DECLERCK, R. Studies on Copular Sentences, Clefts and Pseudoclefts. Dordrecht: Leuven University Press, 1988.

DIESING, M. Indefinites. Cambridge, Massachusetts: MIT Press, 1992.

DORON, E. Verbless Predicates in Hebrew. Tese (Doutorado em Linguística), University of Texas at Austin, 1983.

DUARTE, M. E. L. Do sujeito nulo ao pronome pleno: a trajetória do sujeito no português do Brasil. In: ROBERTS, I.; KATO, M. A. (Orgs). Português brasileiro: uma viagem diacrônica. Campinas: Editora da UNICAMP, 1993.

FARIAS, J. G. de. Aspectos da Sintaxe de Preposições no Português. 300 f. Tese (Doutorado em Linguística), Faculdade de Letras, Universidade Federal de Alagoas. Maceió, 2005. 
FERREIRA DA SILVA, J. “Onde está Madrid?”, “Onde é Madrid?" e “Onde fica Madrid?”. Ms. Universidade de Bochum, 2004.

FOLLI, R.; HARLEY, H. Consuming Results in Italian and English: Flavors of v. In: KEMPCHINSKY, P.; SLABAKOVA, S. (Eds.). Aspectual Inquiries. Dordrecht: Springer, 2005. pp. 95-120.

GONÇALVES, E. Construções existenciais com o verbo ser no português europeu escrito: Um estudo comparativo. Anais do SETA, n. 4, IEL/UNICAMP, 2010.

GREENBERG, Y. Hebrew Nominal Sentences and the Stage/ Level Distinction. M.A.Thesis, Bar Ilan University, Israel, 1994.

GUILHERME, A. R. Era chegado ho tempo. Um contributo para o estudo da construção Ser + Particípio Passado em Português antigo. Dissertação (Mestrado em Linguística). Faculdade de Letras, Universidade de Lisboa, 2009.

HALE, K.; KEYSER, S. J. On Argument Structure and the Lexical Expression of Syntactic Relations. In: HALE, K.; KEYSER, S. J. (Eds.). The View from Building 20: Essays in Linguistics in Honor of Sylvain Bromberger. Cambridge, Mass.: The MIT Press, 1993. pp. 53-109.

HALE, K.; KEYSER, S. J. A Prolegomenon to a Theory of Argument Structure. Cambridge, MA: MIT Press, 2002.

HALLE, M.; MARANTZ, A. Distributed Morphology and the Pieces of Inflection. In: HALE, K.; KEYSER, S. J. (Eds.). The View from Building 20: Essays in honor of Sylvain Bromberger. Cambridge, Mass.: MIT Press, 1993. pp. 111-176.

HARLEY, H. Subjects, Events, and Licensing. Tese (Doutorado em Linguística), MIT, Massachusetts, 1995. 
HARLEY, H. How Do Verbs Get Their Names? Denominal Verbs, Manner Incorporation, and the Ontology of Verbs Roots in English. In: ERTESCHIK-SHIR, N.; RAPOPORT, T. (Eds.). The Syntax of Aspect: Deriving Thematic and Aspectual Interpretation. Oxford (New York): Oxford University Press, 2005. pp. 42-64.

HIGGINS, F. R. The Pseudo-Cleft Construction in English. Tese (Doutorado em Linguística), Indiana University Linguistics Club, 1976.

KATO, M. A. A evolução da noção de parâmetros. D.E.L.T.A. v.18. no 2, 2002. pp. 309-337.

KRATZER, A. Stage-Level and Individual-Level Predicates. In: CARLSON, G. N.; PELLETIER, F. J. (Eds). The Generic Book. Chicago: The University of Chicago Press, 1995. pp. 125-175.

KROCH, A. Reflexes of Grammar in Patterns of Language Change. Language Variation and Change, 1, 3, 1989. p. 199-244.

LABOV, W. Sociolinguistic patterns. Philadelphia, University of Pennsylvania Press, 1972.

LABOV, W. Principles of Linguistic Change: Internal Factors. Volume 1: Internal Factors. Cambridge: Beackwell Publishers, 1994.

MARANTZ, A. No Escape from Syntax: Don't Try Morphological Analysis in the Privacy of Your Own Lexicon. Proceedings of the 21st Penn Linguistics Colloquium, 1997. pp. 201-225.

MATTOS E SILVA, R. V. O Português arcaico: fonologia, morfologia e sintaxe. São Paulo: Contexto, 2006.

MEALHA, I. F. 'Não sou ministro, estou ministo': a selecção de ser/ estar. Polifonia, Lisboa, Edições Colibri, n. 4, 2001. pp. 153-163. 
MIOTO, C.; FIGUEIREDO SILVA, M. C.; LOPES, R. E. Novo manual de sintaxe. Florianópolis: Insular, 2004.

MORO, A. The Raising of Predicates: Predicative Noun Phrases and the Theory of Clause Structure. Cambridge: Cambridge University Press, 1997.

PAIXÃO DE SOUSA, M. C. Língua Barroca: sintaxe e história do português nos anos 1600. 377 f. Tese (Doutorado em Linguística). Instituto de Estudos da Linguagem. UNICAMP, Campinas, 2004.

PAIXÃO DE SOUSA, M. C. Memórias do texto: aspectos tecnológicos na construção de um corpus histórico do português. Projeto de Pesquisa, 2005.

PARTEE, B. H. Copula Inversion Puzzles in English and Russian. In: DZIWIREK, K.; COATS, H.; VAKARELIYSKA, C. M. (Eds.). Annual Workshop on Formal Approaches to Slavic Linguistics. Ann Arbor, MI: Michigan Slavic Publishers, 1999. p. 361-396.

PERELTSVAIG, A. On the Nature of Intra-Clausal Relations: A Study of Copular Sentences in Russian and Italian. $\mathrm{PhD}$ Dissertation: McGill University, 2001.

PERINI, M. A. Princípios de linguística descritiva. São Paulo: Parábola, 2006.

PUSTET, R. Copulas: Universals in the Categorization of the Lexicon. Oxford: Oxford University Press, 2003.

RAPOPORT, T. R. Copular, Nominal and Small Clauses: A Study of Israeli Hebrew. Ph.D. dissertation, MIT, 1987.

RAPOSO, E. P. Teoria da gramática: a faculdade da linguagem. Lisboa: Caminho, 1992. 
RIBEIRO, I. A formação dos tempos compostos: a evolução histórica das formas TER, HAVER E SER. In: ROBERTS, I.; KATO, M. A. Português brasileiro. Uma viagem diacrônica. Campinas: UNICAMP, 1996.

RIEMSDIJK, H. V.; WILLIAMS, E. Introdução à teoria da gramática. São Paulo: Martins Fontes, 1991.

RUSSEL, Bertrand. The Philosophy of Mathematics. London: Allen \& Unwin, 1919.

SCHMITT, C. Semi-Copulas: Event and Aspectual Composition. In: KEMPCHINSKY, P.; SLABAKOVA, R. (Eds.). Syntax, Semantics and the Acquisition of Aspect. Dordrecht: Kluwer, 2005.

SEUREN, Pieter. Western Linguistics: An Historical Introduction. Oxford: Blackwell, 1998.

TAVARES SILVA, C. R. A natureza de Agr e suas implicações na ordem VS: um estudo comparativo entre o Português Brasileiro e o Português Europeu. 613 f. Tese (Doutorado em Linguística). Faculdade de Letras, Universidade Federal de Alagoas, Maceió, 2004.

TORRES MORAIS, M. A. C. R. Aspectos diacrônicos do movimento do verbo, estrutura da frase e caso nominativo no português do Brasil. In: ROBERTS, Ian; KATO, Mary A. (Orgs). Português brasileiro: uma viagem diacrônica. Campinas: Editora da UNICAMP, 1993.

VIOTTI, E. 1999. A sintaxe das sentenças existenciais no português do Brasil. 300 f. Tese (Doutorado em Linguística). Departamento de Linguística. Universidade de São Paulo, São Paulo, 1999.

VITÓRIO, E. G. de S. L. A. Ter/ haver existenciais na escrita dos alunos de ensino fundamental e médio da cidade de Maceió/ AL. 121 f. Dissertação (Mestrado em Linguística). Faculdade de Letras. Universidade Federal de Alagoas, Maceió, 2008. 
WEINREICH, U.; LABOV, W.; HERZOG, M. Empirical

Foundations for a Theory of Language Change. In: W.

Lehman; Y. Malkiel. (Eds.). Directions for Historical

Linguistics. Austin: University of Texas Press, 1968. p. 97-195. 